\title{
Plasticidade de glândulas tegumentares abdominais em Monoeca xanthopyga Harter-Marques, Cunha \& Moure (Hymenoptera, Apidae, Tapinotaspidini)
}

\author{
Camila Gonçalves dos Santos ${ }^{1}$, Juliano Morales de Oliveira ${ }^{1}$, Kelli dos Santos Ramos ${ }^{1} \&$ Betina Blochtein ${ }^{1}$
}

${ }^{1}$ Pontifícia Universidade Católica do Rio Grande do Sul, Faculdade de Biociências, Laboratório de Histologia. Av. Ipiranga 6681, prédio 12C sala 144, 90619-900 Porto Alegre-RS, Brasil.

\begin{abstract}
Plasticity of abdominal tegumentar glands in Monoeca xanthopyga Harter-Marques, Cunha \& Moure (Hymenoptera, Apidae, Tapinotaspidini). Tegumentar glands are highly known in social bees and are responsible for a diversity of functions in these insects. However, little is known about these glands in solitary bees. Monoeca xanthopyga is a solitary bee species that shows a singular behavior of mating and nesting. This study is to verify the occurrence of abdominal tegumentar glands and the chemical nature of the products secreted by males and females of M. xanthopyga, at two moments of the vital cycle: just emerged and at the nesting period. The material was studied using light and scanning electron microscopy and histochemistry. Males and females just emerged and at nesting period show tegumentar glands on terga III to VII, however differ on the type and location. On sterna of a just emerged female tegumentar glands were not detected, while those in nesting period present glands at sterna IV to VI. In males, the tegumentar glands show on sterna IV to VI. The histochemical analysis of the tegumentar glands of males and females suggest predominance of lipid-nature products, possibly involved in the communication related to the sexual behavior.
\end{abstract}

KEYWORDs. Histology; solitary bee; tegumentar glands.

REsumo. Glândulas tegumentares são amplamente conhecidas em abelhas sociais e responsáveis por diversas funções nestes insetos. Entretanto, pouco se conhece sobre estas glândulas em abelhas solitárias. Monoeca xanthopyga é uma espécie de abelha solitária que exibe comportamento peculiar nas estratégias de acasalamento e no processo de nidificação. Este estudo visa verificar a ocorrência de glândulas tegumentares abdominais e a natureza química de produtos secretados por machos e fêmeas de $M$. xanthopyga, em dois momentos do ciclo vital: recém-emergidas e em período de nidificação. O material foi estudado utilizando-se microscopia óptica e eletrônica de varredura e histoquímica. Machos e fêmeas recém-emergidas e em período de nidificação apresentam glândulas tegumentares nos tergos III ao VII, entretanto diferem no tipo e na localização. Nos esternos de fêmeas recém-emergidas, as glândulas estão ausentes, já nas fêmeas em período de nidificação estas glândulas estão presentes nos esternos IV ao VI. Nos machos, as glândulas tegumentares estão presentes nos esternos IV ao VI. A análise histoquímica das glândulas tegumentares de machos e fêmeas sugere a presença de produtos de natureza lipídica, possivelmente envolvidos na comunicação relacionada ao comportamento sexual.

Palavras-Chave. Abelhas solitárias; glândulas tegumentares; histologia.

Os himenópteros apresentam uma diversidade de glândulas exócrinas de origem ectodérmica distribuídas por todo o corpo (Post \& JeAnne 1982; Billen 1991). Nas abelhas, estudos registraram glândulas em diferentes partes do corpo (CRUZLandim 1967; Costa \& Cruz-Landim 1977; Cruz-Landim et al. 1980; Iide et al. 1993; Salles \& Cruz-Landim 1998; Cruz-Landim \& Abdalla 2002) como cabeça (Kerr \& CRUZ 1961; CANe et al. 1983; CAVASIn-Oliveira \& CruZ-LANDim 1998), tórax (CruZLandim 1973; CRUZ-Landim \& Reginato 1999), abdome (Mota \& Cruz-Landim 1988; Cunha et al. 1990; Cruz-Landim \& Mota 1993; Cassier \& Lensky 1994; Guerino \& Cruz-Landim 1999; Santos \& Blochtein 2000) e pernas (Williams et al. 1984; Coville et al. 1986; Cruz-Landim \& Moraes 1994; Wittmann \& Blochtein 1995; CruZ-Landim 1997; Franco \& CruZ-Landim 1999; CRUZ-LANDIM \& FRANCO 2000).

Glândulas exócrinas resultantes de modificações da epiderme, denominadas tegumentares, são nas abelhas classificadas de acordo com o modo de liberação de seus produtos: na Classe I, a secreção produzida pelo epitélio é exteriorizada através da cutícula e na Classe III, unidades glandulares, destacadas da epiderme, liberam seus produtos para o exterior por um canal cuticular (NOIROT \& QUENNEDEY 1974, 1991).

Estudos com abelhas revelam que determinadas glândulas tegumentares estão diretamente envolvidas na produção de cera (Apina e Meliponina) ou de feromônios, indispensáveis na comunicação intraespecífica (CRUZ-LANDIM 1967; SALLES \& Cruz-Landim 1998; Guerino \& Cruz-Landim 1999).

A estratégia de acasalamento dos machos de Monoeca xanthopyga Harter-Marques, Cunha \& Moure, 2001, observada em condições naturais por CunHa \& Blochtein (2002), evidenciou que eles patrulhavam agregações de ninhos ativamente à procura de fêmeas emergentes. Uma fêmea em fase de emergência, ainda antes de sair do ninho, atraía vários machos que aglomeravam-se junto à abertura do ninho e disputavam a posse da mesma. Após o acasalamento, os machos retornavam ao comportamento de patrulha e as fêmeas iniciavam a construção de seus ninhos e não mais demonstravam atratividade.

Este estudo objetivou a comparação da ocorrência de 
glândulas tegumentares abdominais e natureza química das secreções em machos e fềmeas recém-emergidas e em período de nidificação de $M$. xanthopyga.

\section{MATERIAL E MÉTODOS}

Fêmeas e machos de M. xanthopyga foram coletados em Cambará do Sul, Rio Grande do Sul, no período de janeiro a março de 1999 e 2000 . As fềmeas recém-emergidas foram obtidas a partir da fixação de armadilhas sobre entradas de ninhos da temporada anterior. As fêmeas em período de nidificação e os machos foram coletados junto aos ninhos, com auxílio de rede entomológica.

Para o estudo histológico e histoquímico, o abdome de cada inseto foi dissecado, fixado em Paraformaldeído 4\% tamponado e incluído em Leica Historesin ${ }^{\circledR}$. Cortes seriados $(3 \mu \mathrm{m})$ foram confeccionados em micrótomo (Leica ${ }^{\circledR}$ RM 2145) utilizando-se navalhas de tungstênio. As secções histológicas foram coradas com Azul de Metileno/Fucsina Básica e, para o estudo histoquímico, usou-se Sudan Black B, Ácido Periódico de Shiff-P.A.S. e Azul de Bromofenol (Humason 1972; SHeEHAN \& HRAPCHAK 1980). A análise das preparações e os registros fotográficos foram procedidos com fotomicroscópio Zeiss Axioskop ${ }^{\circledR}$.

O estudo morfológico e registros fotográficos das placas abdominais das fêmeas em período de nidificação foram feitos com o auxílio de microscópio eletrônico de varredura (Philips XL $30^{\circledR}$ ), a partir de espécimes tratados com KOH 5\%, desidratados e metalizados.

Os espécimes coligidos foram depositados na coleção de abelhas do Museu de Ciências e Tecnologia da PUCRS e as preparações histológicas permanentes incluídas na coleção do Laboratório de Histologia da Faculdade de Biociências da PUCRS.

\section{RESULTADOS E DISCUSSÃO}

Glândulas tergais. Fêmeas recém-emergidas e em período de nidificação e machos de $M$. xanthopyga apresentam glândulas tegumentares nos tergos III a VII (Fig. 1). As glândulas da Classe I (Fig. 2A) estão presentes nas fêmeas recém-emergidas somente no tergo VII, enquanto nas fêmeas em período de nidificação também encontram-se nos tergos III e VI. No entanto, nos machos, essas glândulas não foram observadas. As glândulas da Classe III (Fig. 2B) de fêmeas nos diferentes períodos estão ligadas às placas tergais III a VI, sendo que nos machos estendem-se também ao tergo VII (Fig. 2D). Os canais quitinosos, típicos de glândulas da Classe III, em M. xanthopyga exibem o canal condutor com textura lisa, que desemboca no exterior através de um orifício (Fig. $3 \mathrm{~A}$ ), e o canal coletor, com formas irregulares e perfurado por poros (Fig. 3B).

Glândulas esternais. Glândulas tegumentares de fêmeas recém-emergidas de $M$. xanthopyga não foram encontradas no esterno. No entanto, glândulas da Classe I foram localizadas

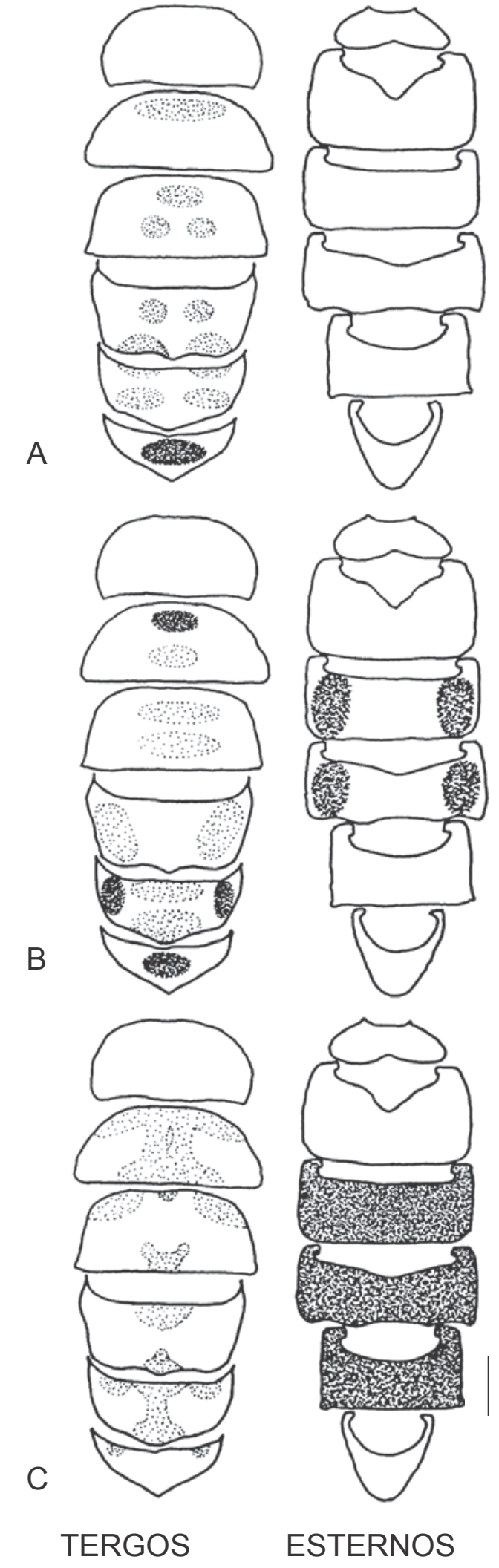

Fig. 1. Esquema dos tergos e esternos de Monoeca xanthopyga evidenciando a localização e classificação das glândulas tegumentares: A, fêmea recém-emergida; B, fêmea em período de nidificação; C, macho. $\square$ glândulas da Classe I e $\square$ glândulas da Classe III. Barra $=1,3 \mathrm{~mm}$ 

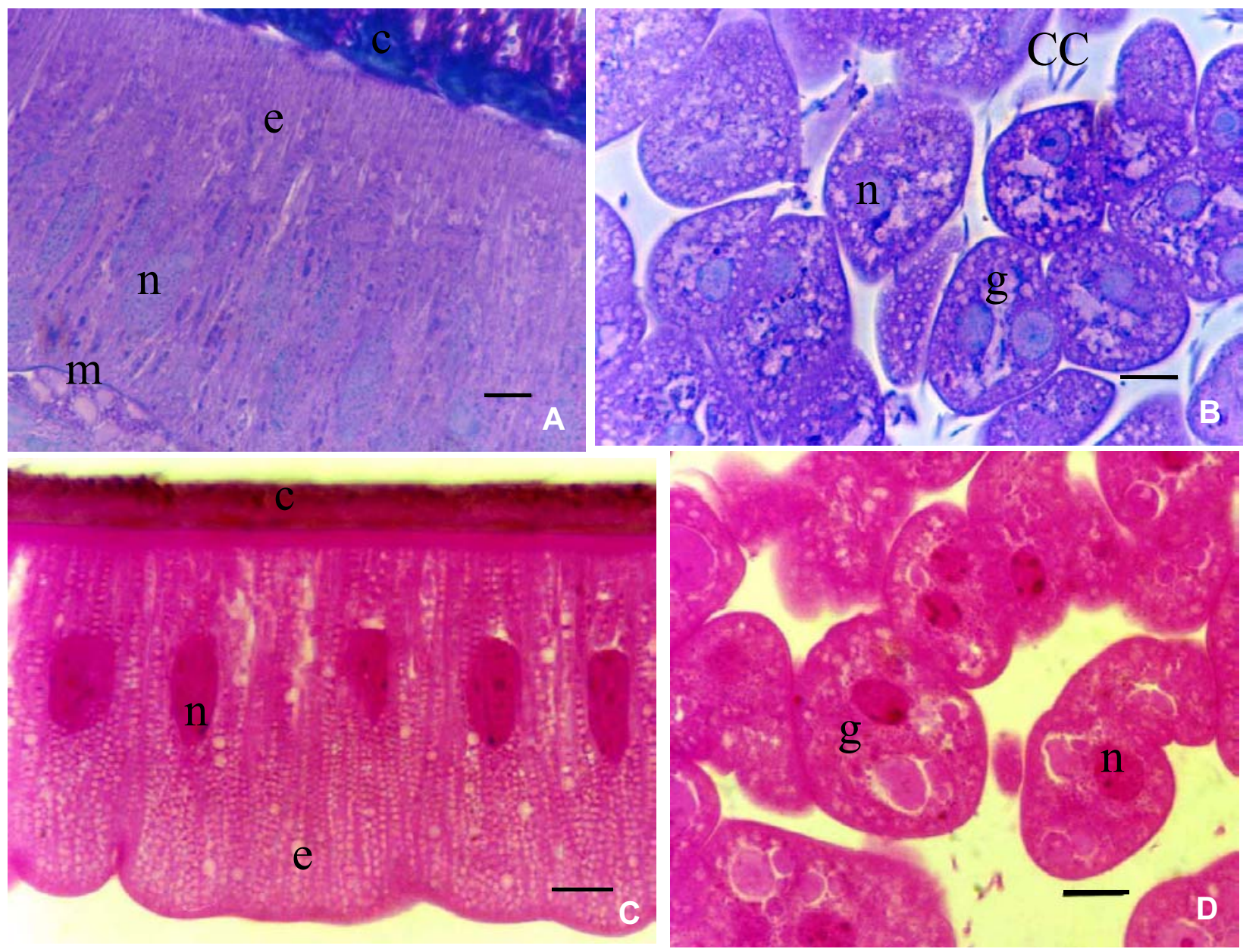

Fig. 2. Monoeca xanthopyga. Fêmea em período de nidificação: A, epitélio secretor do tergo VI; B, unidades glandulares no tergo V. Macho: C, epitélio secretor no esterno III; D, unidades glandulares no tergo IV; c=cutícula; CC=canal condutor; e=epitélio secretor; g=unidade glandular; $\mathrm{m}=$ membrana basal; $\mathrm{n}=$ núcleo. Barra=8,4 $4 \mathrm{~m}$. Coloração com fucsina básica/azul de metileno.

nos esternos IV e V das fêmeas em período de nidificação e nos machos nos esternos IV a VI (Fig. 2C). A diferença intraespecífica quanto a ocorrência e ao tipo de glândulas tegumentares de machos e fêmeas nos dois períodos de ciclo vital é evidente.

Plasticidade das glândulas tegumentares. Nas fêmeas recém-emergidas e em período de nidificação, a ocorrência das glândulas da Classe I difere quanto aos tergos. Nota-se, nas fêmeas em período de nidificação, o aumento da área glandular resultante do surgimento destas nos tergos III e VI. Esta constatação está em consonância com CRUZ-LANDIM \& AbDalla (2002) que afirmam que as glândulas da Classe I surgem após a emergência do indivíduo e seu estado de desenvolvimento está relacionado à determinada função. Glândulas da Classe III em fêmeas em período de nidificação apresentaram distribuição semelhante nos tergos, mas uma maior superfície glandular do que em fêmeas recém-emergidas. Os mesmos autores acrescentam que essas glândulas surgem na fase de pré-pupa e apresentam-se funcionais apenas em certas fases da vida do indivíduo.

Estudos desenvolvidos por SAntos \& Blochtein (2000) a respeito da abelha solitária Ancyloscelis apiformis Fabricius, 1793 (Apidae) mostram que fêmeas apresentam glândulas da Classe III nos esternos IV e V. Fêmeas de Thygater analis Lepeletier, 1841, da mesma família, estudada por STAURENGODA-CunHA et al. (1990) apresentam glândulas da Classe I nos tergos VI e VII e no esterno VI e da Classe III nos esternos V e VI. As abelhas solitárias utilizadas nos estudos citados foram coletadas em flores, impedindo a determinação da idade dos indivíduos. Independente da etapa do ciclo vital, as fêmeas de Apidae apresentam claras diferenças interespecíficas quanto a ocorrência de glândulas tegumentares abdominais.

Resultados dos testes histoquímicos indicam que as glândulas da Classe I presentes no tegumento abdominal de fêmeas e machos de M. xanthopyga apresentam-se negativas ao P.A.S. e ao Azul de Bromofenol, e fracamente positivas ao Sudan Black B. Glândulas da Classe III, em ambos sexos, apresentam-se negativas aos corantes histoquímicos utilizados. GUERINO \& CRUZ-LANDIM (1999) propuseram que 

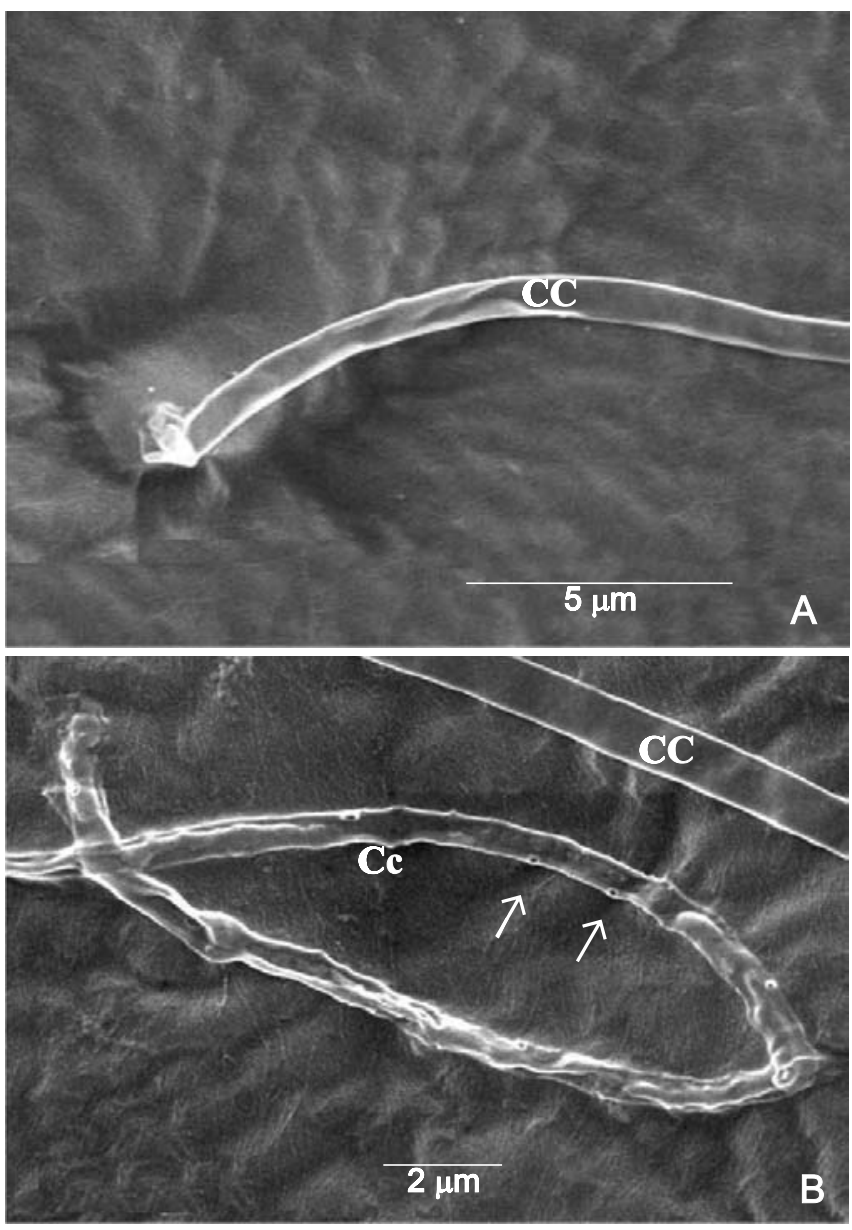

Fig. 3. Ultraestrutura do canal quitinoso de glândula da Classe III. A, canal condutor $(\mathrm{CC})$; B, canal coletor $(\mathrm{Cc})$ e poros (setas).

glândulas com liberação contínua das secreções produzidas possam resultar em leituras fracamente positivas. De fato, nas glândulas tegumentares abdominais de $M$. xanthopyga não houve a constatação de reservatórios de produtos. A secreção liberada pelas glândulas das fêmeas e machos indica a presença de substâncias de natureza lipídica. Essas glândulas tegumentares podem estar relacionadas à comunicação química da espécie.

Agradecimentos. A Rodrigo da Cunha pelas coletas das abelhas em campo. Ao financiamento do Convênio Tübingen/PUCRS e ao CNPq/ PIBIC.

\section{REFERÊNCIAS}

BiLlen, J. 1991. Ultrastructural organization of the exocrine glands in ants. Ethology Ecology \& Evolution 1: 67-73.

Cane, J. H.; S. Gerdin \& G. Wife. 1983. Mandibular gland secretions of solitary bees (Hymenoptera: Apoidea): potencial for nest cell disinfection. Journal of the Kansas Entomological Society
56(2): 199-204.

CAssier, P. \& Y. Lensky. 1994. The nassanov gland of the workers of the honeybee (Apis mellifera L.): ultrastructure and behavioural function of the terpenoid and protein components. Journal of Insect Physiology 40(7): 577-584.

Cavasin-Oliveira, G. M. \& C. Cruz-Landim. 1998. Ultrastructure of Apoidea (Hymenoptera, Anthophorinae) salivary glands. I. Alveolar glands. Revista Brasileira de Entomologia 42(1/2): 1-6.

Costa, A. M. F. \& C. Cruz-Landim. 1977. Estudo comparativo das glândulas do sistema salivar dos Apidae sociais (Hymenoptera). Revista Brasileira de Biologia 37(3): 649-663.

Coville, R. E.; G. W. Frankie; S. L. Buchmann; S. B. Vinson \& H. J. Williams. 1986. Nesting and male behavior of Centris heithausi (Hymenoptera: Anthophoridae) in Costa Rica with chemical analysis of the hindleg glands of males. Journal of the Kansas Entomological Society 59(2): 325-336.

Cruz-Landim, C. 1967. Estudo comparativo de algumas glândulas das abelhas (Hymenoptera, Apoidea) e respectivas implicações evolutivas. Arquivos de Zoologia 3(15): 177-290.

Cruz-Landim, C. 1973. Tipos de glândulas salivares do tórax presentes em abelhas (Hym., Apoidea). Studia Entomologica 16(1-4): 209215

Cruz-LAndim, C. 1997. Glandular sources of exocrines secretions present in bee legs. Brazilian Journal of Morphological Sciences 14(1): 59 .

Cruz-Landim, C.; M. A. C. Hofling \& V. L. Imperatriz-Fonseca. 1980. Tergal and mandibular glands in queen of Paratrigona subnuda (Moure) (Hymenoptera, Apidae). Morphology and associated behaviour. Naturalia 5: 121-133.

Cruz-Landim, C. \& M. H. V. B. Mota. 1993. Differences between the female castes and males of Scaptotrigona postica depilis (Hymenoptera, Apidae, Meliponinae) in the occurence and ultrastructure of tegumentary exocrine glands. Naturalia 18: 173187.

Cruz-Landim, C. \& R. L. M. Silva-de-Moraes. 1994. Ultrastructural localization of new exocrine glands in legs of social Apidae (Hymenoptera) workers. Journal of Advanced Zoology 15(2): 60-67.

Cruz-Landim, C. \& R. D. Reginato. 1999. Preliminar report on the presence of tegumentar glands in the thorax of meliponinae bees (Hymenoptera, Apidae). Revista Brasileira de Biologia 59(1): $167-172$.

Cruz-Landim, C. \& A. C. Franco. 2000. Epithelial bags inside the tibia and femur of males of Centris (Hymenoptera, Anthophoridae): localization and ultrastructure. Revista Brasileira de Entomologia 44(3/4): 97-103.

Cruz-Landim, C. \& F. C. Abdalla. 2002. Glândulas exócrinas das abelhas. Ribeirão Preto, FUNPEC-RP, 181p.

Cunha, R. \& B. Blochtein. 2002. Estrutura de ninhos de Monoeca xanthopyga (Hymenoptera, Apoidea, Tapinotaspidini) no Planalto das Araucárias, Rio Grande do Sul, Brasil. Biociências 10(1): $25-$ 33

Franco, A. C. \& C. Cruz-Landim. 1999. Ocorrência e morfologia de glândulas nas pernas de Centris e Epicharis (Hymenoptera, Anthophoridae). Revista Brasileira de Zoologia 16(supl. 2): 110 .

Guerino, A. C. \& C. Cruz-Landim. 1999. A new type of sternal gland present in Oxaea flavescens (Hymenoptera, Oxaeinae): location and histology. Cytobios 97: 71-77.

Harter-Marques, B.; R. Cunha \& J. S. Moure. 2001. Uma nova espécie de Monoeca (Hymenoptera, Apoidea, Tapinotaspidini) do Planalto das Araucárias, no Rio Grande do Sul, Brasil. Biociências 9(1): 99-110.

Humason, G. L. 1972. Animal Tissue Techniques. San Francisco, W.H. Freeman and Company, 641p.

Iide, A. A.; M. A. Staurengo-da-Cunha \& J. V. Betioli. 1993. Desenvolvimento das glândulas mandibulares e abdominais de Nannotrigona testaceicornis (Lepeletier, 1836) (Hymenoptera, Apidae). Naturalia 18: 157-172. 
Kerr, W. E. \& C. C. Cruz. 1961. Funções diferentes tomadas pela glândula mandibular na evolução das abelhas em geral e em "Trigona (Oxytrigona) tataira" em especial. Revista Brasileira de Biologia 21(1): 1-16.

Mota, M. H. V. B. \& C. Cruz-Landim. 1988. Ocorrência e morfologia de glândulas tegumentares abdominais em Apis mellifera L. (Hymenoptera, Apidae). Revista Brasileira de Zoologia 5: 119154.

Noirot, C. \& A. Quennedey. 1974. Fine structure of insect epidermal glands. Annual Review of Entomology 19: 61-80.

Noirot, C. \& A. Quennedey. 1991. Glands, gland cells, glandular units: some comments on terminology and classification. Annales de la Société Entomologique de France 2(27): 123-128.

Post, D. C. \& R. L. Jeanne. 1982. Sternal glands in three species of male social wasps of the genus Mischocyttarus (Hymenoptera: Vespidae). Journal of the New York Entomological Society 90(1): 8-15.

Salles, H. C \& C. Cruz-Landim. 1998. Levantamento das glândulas exócrinas presentes em Camargoia nordestina Moure, 1989 (Hymenoptera, Apidae, Meliponinae). Revista Brasileira de
Entomologia 41(2-4): 297-302.

Santos, C. G. \& B. Blochtein. 2000. Glândulas tegumentares abdominais em Ancyloscelis apiformis Fabricius, 1793 (Hymenoptera, Anthophoridae). Biociências 8(1): 65-72.

Sheehan, D. C. \& B. B. HrapchaK. 1980. Theory and practice of histotechnology. Saint Louis, Mosley Company, 472p.

Staurengo-da-Cunha, M. A.; C. Cruz-Landim \& L. A. O. Campos. 1990. Ocorrência e morfologia das glândulas tegumentares de algumas espécies de abelhas (Hymenoptera, Apoidea). Naturalia 15: 209. 217.

Williams, H. J.; S. B. Vinson; G. W. Frankie; R. E. Coville \& G. W. Ivie. 1984. Morphology, chemical contents and possible function of the tibial gland of males of the Costa Rican solitary bees Centris nitida and Centris trigonoides subtarsata (Hymenoptera: Anthophoridae). Journal of the Kansas Entomological Society 57(1): 50-54.

Wittmann, D. \& B. Blochtein. 1995. Why males of leafcutter bees hold the females' antennae with their front legs during mating. Apidologie 26: 181-195 